\title{
Geological and Geomorphological Factors of Natural Hazards in Ukrainian Carpathians
}

\author{
Olena Ivanik ${ }^{1 *}$, Viktor Shevchuk', Dmytro Kravchenko', \\ Serge Shpyrko', Vitalii Yanchenko', Kateryna Gadiatska' \\ 1 Department of General and Historical Geology, Institute of Geology, Taras Shevchenko National University of \\ Kyiv, 60, Volodymyrska str., Kyiv, Ukraine \\ * Corresponding author's e-mail: om.ivanik@gmail.com
}

\begin{abstract}
The consideration was given to the geological and geomorphological factors of natural hazards in the Ukrainian Carpathians. Principal impact of rock lithology, geomorphological structure, underwater regime and seismic processes on the erosion, gravitational and water-gravitational processes formation was demonstrated. The research confirmed a special role of the tectonic factor and the presence of weak zones in the development of natural hazards. Weak zones are characterized by fracturing, brecciation, bedding of flysch deposits and contrast in permeability. The strength properties of rocks decrease drastically within such zones, and large-scale landslide formation processes occur, especially in the case of subparallel location of zones, relative to river valleys and slopes. The factors of hazardous geological processes were defined and classified using GIS analysis and the developed geological model. A conceptual model of landslide hazards in the area of Carpathian Mountains was developed. Weight coefficients of potentially landslide prone factors were determined from the on-site observations and archive data. An integral spatial map of landslide susceptibility was proposed. The results of this research were the basis of geological environment modeling for the assessment of hazardous geological processes impact on the functioning of infrastructure objects.
\end{abstract}

Keywords: geomorphological factors, natural hazards, landslide hazards, landslide susceptibility, conceptual model, integral spatial map, Ukrainian Carpathians.

\section{INTRODUCTION}

Environmental protection is now a major focus of many countries and the international community as a whole. Environmental factors have repeatedly been the cause of many accidents, such as landslides, flooding, seismic events and other environmental disasters. Natural hazards cause substantial damage in the Ukrainian Carpathians. This area has a well-developed infrastructure with many roads, bridges, railways, pipelines, commercial and residential structures. Sometimes, hazardous geological processes disrupt sustainable development of this area and cause many crises.

Usually, the hazardous situations under various climatic and landscape zones are mostly related to the action of natural, in particular, geological and geomorphological factors. The research on hazardous geological processes underlines the effectiveness of geomodelling and GIS-analysis in predicting the negative impact of flooding processes, landslides, debris flows, etc. [Foster et al., 2012; Garcia-Rodriguez et al., 2008; Pelletier, 2008; Wu, 2015; Varnes, 1978; Varnes \& Savage, 1996]. Geomodelling and GIS are used for inventory mapping, obtaining an estimate of the likely development of natural hazards processes, as well as development models for spatial analysis. Hence, the risks of natural hazards are estimated on the basis of geological field observations, statistical analysis and remote sensing data. A great importance is given to a complex of geological, geomorphological, geophysical and 
remote methods for the monitoring of hazardous geological processes [Jaboyedoff et al., 2010].

Numerous research groups have contributed to the studies of natural hazards in the Carpathian Mountains. As a result, vast knowledge and data have been collected pertaining to the distribution and characterization of these phenomena, in particular landslides, debris flows, river erosion, avalanches, etc. However, most of these studies are of merely regional wide extension, focusing on general distribution maps of exogenic processes. Detailed studies of hazardous phenomena are a necessity for a comprehensive analysis of the geological and geomorphological factors contributing to their formation, increasing credibility of both their assessment and prognosis within certain territories.

As a testing site for the investigation of natural hazard processes we selected an area, located in Volovets and Svalyava districts of Transcarpathian Region of Ukraine with the area above $804 \mathrm{~km}^{2}$ (Figure 1). This area features active development of floods, landslide processes, debris flows, and side erosion of river beds.

This area presents a high grade of industrial load on the geological environment, which favors the background for the intensification of hazardous processes. This load is conditioned by increased concentration of overland and underground utilities, the most important of which is the trunk railroad line, several state roads and multitude of local mainroads, as well as a network of transnational oil and gas pipelines. All these objects are known by complicated maintenance with periodically emerging hazardous incidents due to natural factors.

\section{Formation factors for natural hazards}

\section{Lithological and stratigraphic factors of natural hazards}

The studied area is characterized by a complicated geology. It features two major structural layers. The occurrence rate of hazardous geological processes is conditioned by this major stratification and depends on the rate and nature of denudation processes within the area.

The lower structural layer is formed by Carpathian Fold Belt, represented by carbonateous and terrigeneous Mesosoic and Cenosoic formations, mostly, by flysch formation, which form several structural and facial zones: Krosno, Duklya, Magura and Porkulets zones (Outer
Carpathians) and Pennine zone (Inner Carpathians). The sediments are intensively displaced and form a series of nappe structures. Main parameters, conditioning lithological and facial differences between rocks are rock composition, relation between different flysch constituents (flysch rhytmicity), color, carbonate, silicate and mica content, enrichment in organics, textural features, fossils, marking horizons and formation thickness. Such properties of flysch formations are constitutive for various exogenous processes, since various types of flysch rocks essentially vary in physical and mechanical properties; hence, they can affect destructive processes in different ways. The deposits of the upper structural layer are formed by Neogene and Quaternary sedimentary, volcanic and volcanomictic rocks with mostly horizontal bedding.

About 220 active and old stabilized landslides are studied and mapped within the area (Figure 2). Most of them are limited within corresponding strata.

Using ESRI's Spatial Analyst module, we performed the attribution of mapped landslides to the distinct lithological and stratigraphical units. A majority of landslides is associated with flysch deposits, formed by interbedded mudstones and marls (18), and predominantly sandstone formations (9). A large number of landslides is located in tuff breccias and tuff of intermediate composition. As to the stratigraphy, the majority of landslides are associated with Chornogolovska suite rocks $\left(\mathrm{K}_{2}-\mathrm{P}_{2} \mathrm{ch}\right)$, composed of interbedded grey mica- carbonateous fine grained sandstones, mudstones and siltstones. Some landslides are also associated with Oligocene flysch deposits. The same operation was performed for the analysis of genetic types of Quaternary deposits where landslides were formed. It was stated that most landslides are associated with colluvial and ancient proluvial deposits.

\section{Structural and tectonic factors of natural hazards}

The study of destruction zones of various ranks in the area and their spatial associations with river valleys allowed to investigate their impact on the development of gravitational and watergravitational processes. Such zones can have subparallel, perpendicular and diagonal orientations related to the river valleys. A dense dislocation network of different ranges, varying from cleavage of different origin up to regional faults results in multiple relations between the structural and 


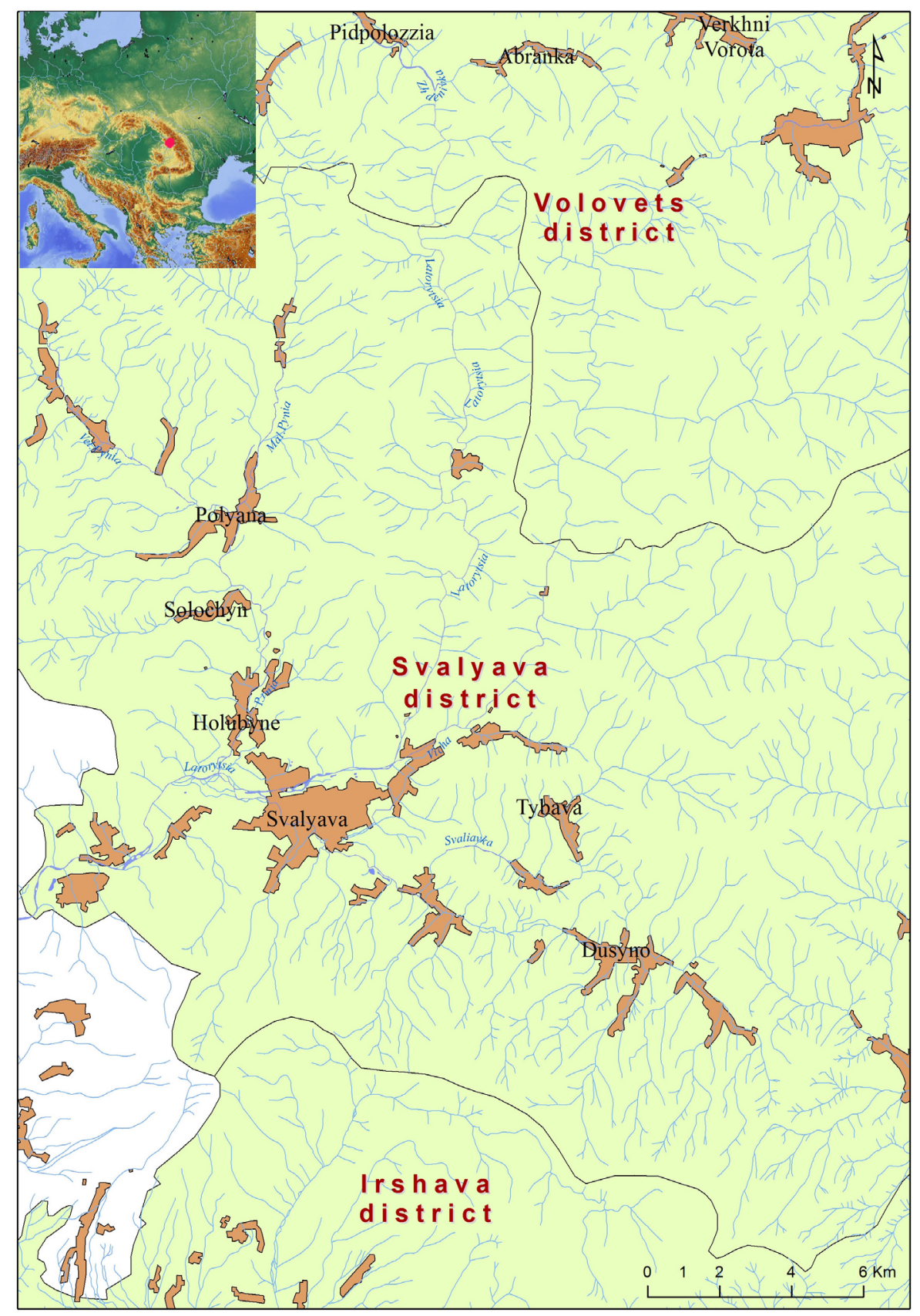

Figure 1. Map of the study area

orographic forms. It is necessary to note that the development of the gravitational and erosion processes is mainly determined by the deformation nature of rocks, types of tectonites, cementation of sediments, hydrogeology, topography etc, that is the factors affecting the mechanical properties of rocks and their response to stress. The range of the fault and the size of the fault zone themselves have only a minor correlation with the above.

We performed field investigations of destructive zones to examine the impact of the structural and tectonic factor on the landslide formation (Figure 3) [Ivanik, 2015].
The distance subroutine of the Spatial Analyst module enabled to confirm the essential role of fracture zones in the landslide formation and their relation with tectonic processes. We established the relation between landslides and fault zones as well as confirmed their spatial associations. The map of distances from landslides to the faults of various kinematic types and ranges (Figure 4) testifies of their spatial correlation. Certain combinations of geological and tectonic conditions can result in a complex interplay of river valleys and tectonic zones, which essentially affects the dynamics and morphology of landslide bodies. The 


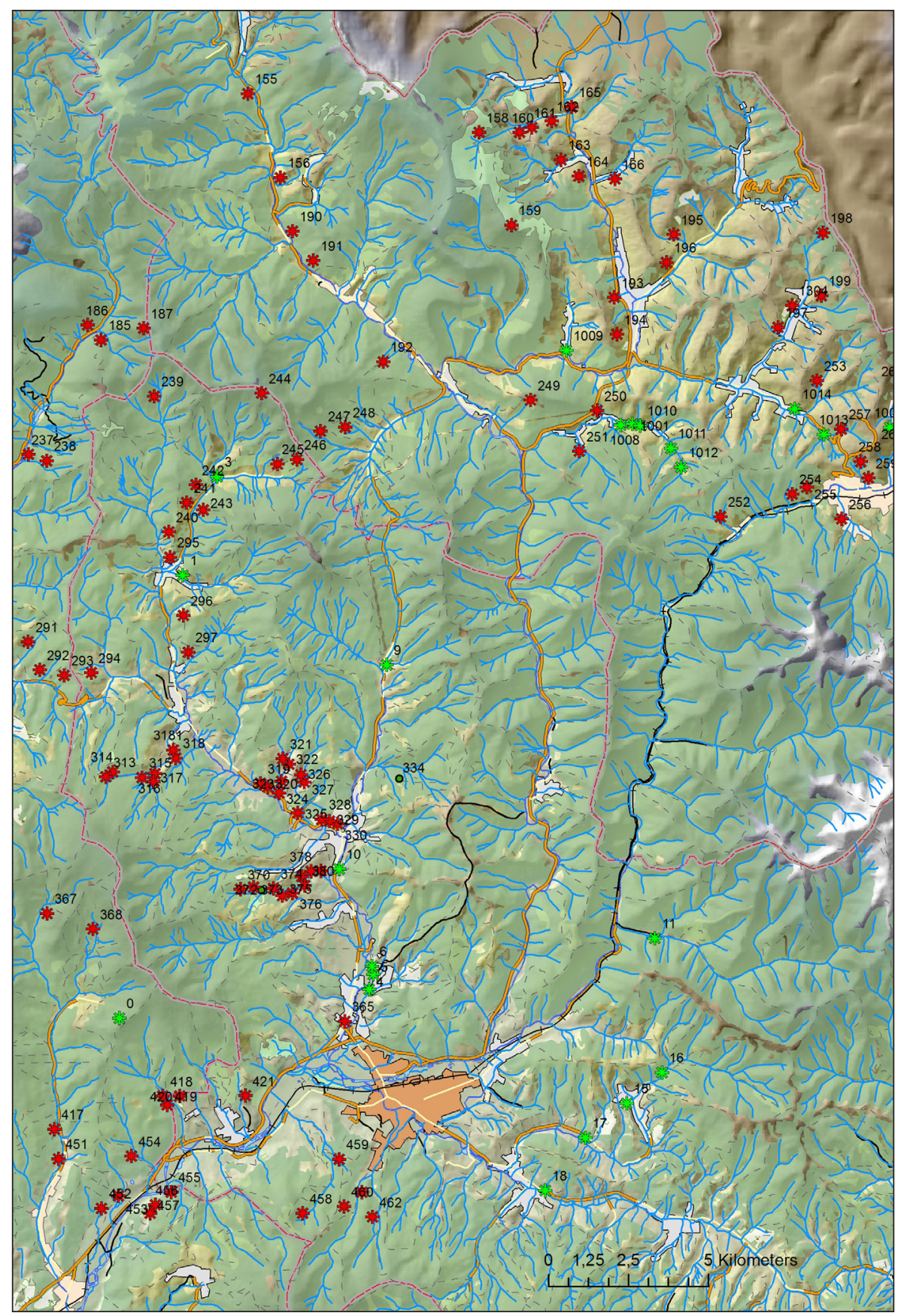

Figure 2. Distribution of active (green color) and stabilized (red color) landslides in Svalyava and Volovets districts, Transcarpathian Region

tectonized beds with dominating mudstone interlayers mostly tend to lose mechanical equilibrium on the slopes, resulting in the development of landslide processes.

\section{Geomorphological factors of natural hazards}

The geomorphological structure of the area is one of the most important criterion and prognostic indicator for the formation of landslides. The horizontal roughness is considerable in the area (up to $2.5 \mathrm{~km} / \mathrm{km}^{2}$ ), vertical roughness reaches
$120 \mathrm{~m}$, and slope inclinations up to $35-40^{\circ}$, which creates necessary energy for various exogenic processes. The main factors, parametrizing the impact of the topography on the development of flood- and gravitational phenomena are: absolute elevation of the landslides, slope and aspect of the hills. In order to study the relief parameters, we created a DEM model representing 3D elevation data (Figure 5).

It was found that the majority of landslides are associated with $13-20^{\circ}$ slopes under 


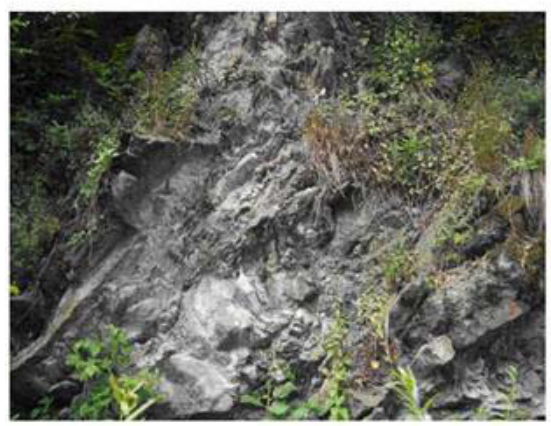

a

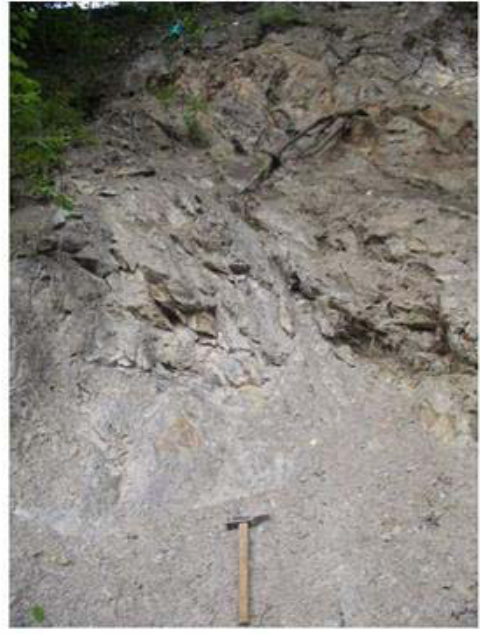

b

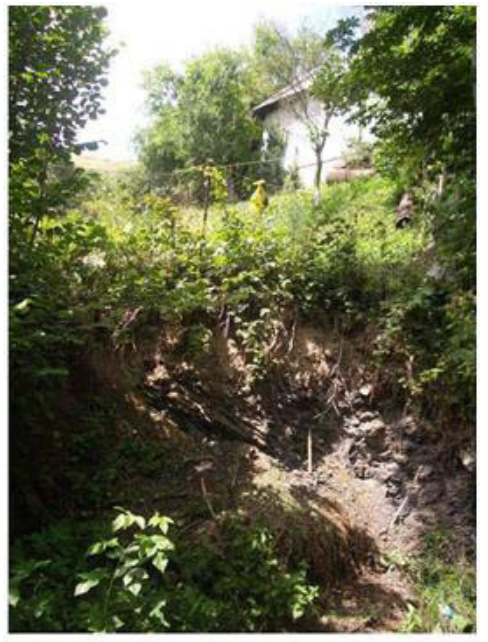

$c$

Figure 3. Destructive zones and landslide in the flysch deposits within the Latoritsa river basin (Carpathians)

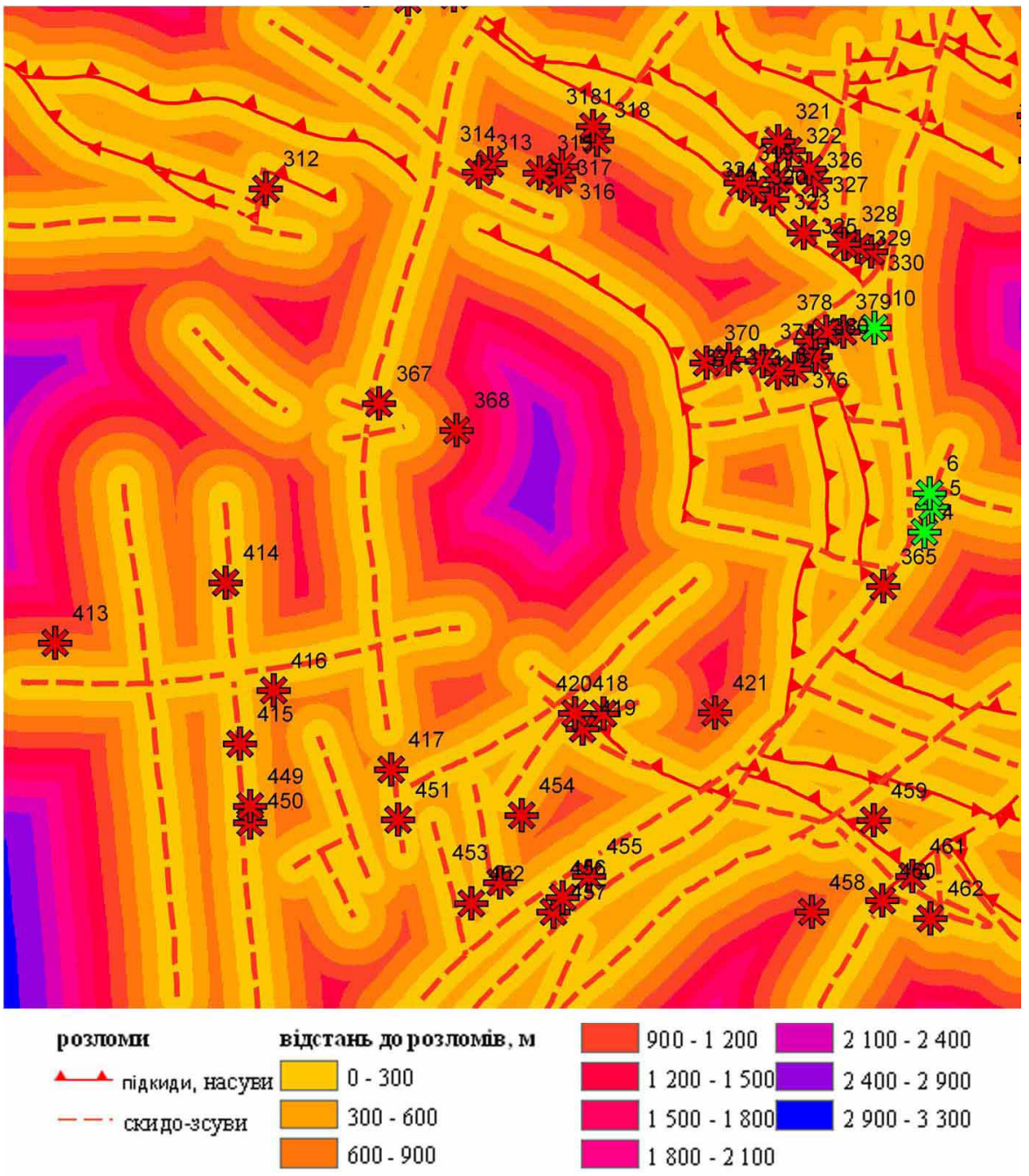

Figure 4. Distance map between landslides and faults 


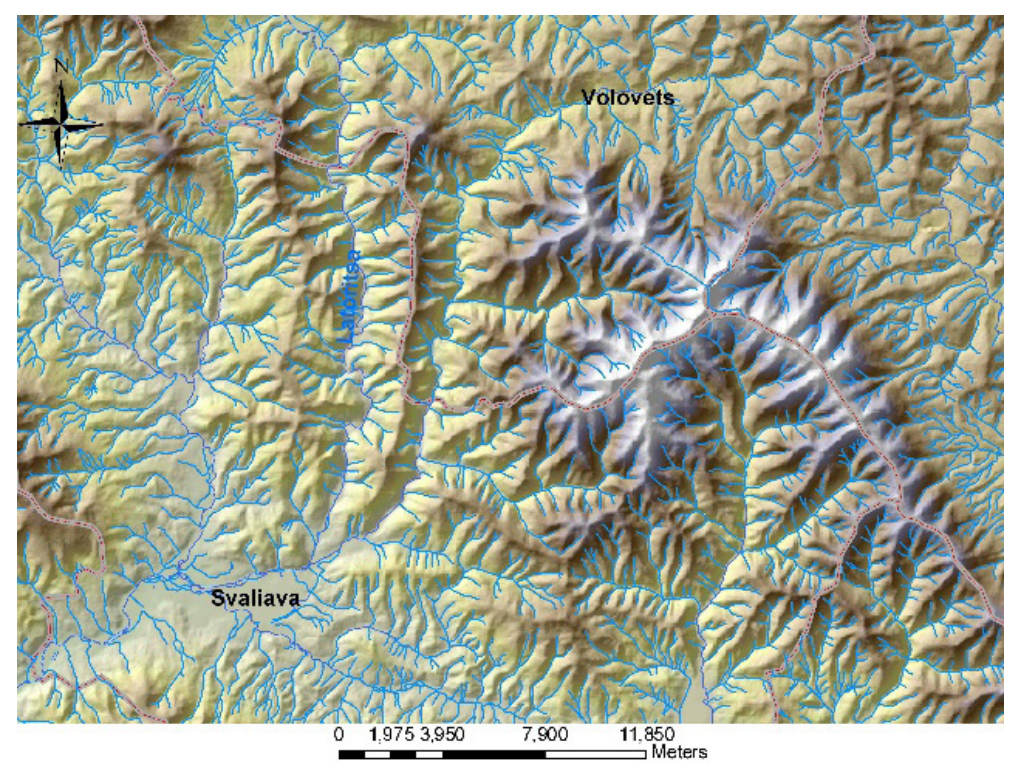

Figure 5. DEM model of relief within Carpathian region

predominantly southern exposition, which is supposedly related with the vegetation coverage of the hill and increased landslide hazards, if it is not covered with grass.

\section{Modern and neotectonic movements and their impact on the development of hazardous processes}

The modern and neotectonic movements are featured with a distinct zonation in the topography of the Ukrainian Carpathians and their impact on the intensification of hazardous geological phenomena is apparent. Such movements are detected throughout the whole area and the general trend is the rising of Carpathians and subsidence of the Transcarpathian Depression. The processes of rising and subsidence are relative and fairly differentiated across the system of faults of general Carpathian trending, which coincide with borders of blocks, nappes and scutes. The accumulated amplitudes of neotectonic movements vary in different structural and facial zones. The highest values are recorded within the Porkuletski nappe (up to 1800-2000 m). The Duklya nappe is characterized by the values of $1200-1600 \mathrm{~m}$, and Krosno zone - 800-1200 m. According to the territory of the area belongs to the zone of intermittent differentiated rising and horizontal movements of the Earth crust, and also to the zone of oscillatory movements (reciprocating movements with a subzone of volcanically driven tectonic processes and associated crust movements). The most active neotectonic risings and horizontal movements of the Earth crust are recorded within the first zone. The average gradients of neotectonic movements within the first zone are $\left(2 \cdot 10^{-4}\right)-\left(7 \cdot 10^{-4}\right) \mathrm{cm} / \mathrm{km} /$ year.

Modern risings are manifested by the formation of narrow V-shaped river valleys. The topographical manifestations of modern tectonic risings are confirmed by the GPS observations of stationary stations within European geoblock of ITRF network (International Terrain Reference Frame), data from which were used for the calculation and mapping of vertical and horizontal shift rates. The velocities of vertical movements within the area are up to $+5 \mathrm{~mm} /$ year.

Therefore, permanent activation of tectonic movements stipulates the rise of the potential energy for the formation of water-erosion and gravitational processes, which together with factors of geomorphological and lithological origin contribute to the intensification of landslide processes.

\section{Hydrogeological factors of landslide processes}

The basin of the Carpathian Fold Belt is characterized by elevated annual precipitation (up to $1600 \mathrm{~mm}$ ), as well as high vertical and horizontal relief roughness; it is a zone of intense water turnover and active phreatic flow with predominant overland discharge. The Carpathian artesian basin is a zone of delayed water turnover and increased mineralization of ground water. The most considerable impact on the formation of hazardous processes is exerted by the nearest to the surface aquifer. Such factors as aquifer depth, flow pattern, surface discharge spots, filtration parameters of the rocks, their permeability etc. are of high importance. 
The aquifers in the Neopleistocene-Holocene alluvial deposits of the floodplain and terraces deposits of the river Latoritsa and its inflows take the most part in the formation of erosive, landslide and flood phenomena. The active impact on the water flow pattern in the area is made by the aquifers of Paleogene flysch complexes, fissure and ground waters, associated with thin sandstone interlayers of the sand- and mudstone flysch, and also massive sandstones with gravelite interlayers. The underground water flow pattern favoring its discharge in the destructive zones results in an essential water encroachement of flysch beds with the outwash of mudstone material. This endangers the stability of the hills and is manifested in the development of negative relief forms.

The hydrometeorological factor, in particular, annual precipitation, has an important impact on the activation of landslide phenomena. In combination with other factors, such as water detension of rocks, infiltration rates and the factors described above, it is a catalyst for landslide formation. In order to analyze the impact of this parameter, the map of annual precipitation (with values ranging from 800 to $1300 \mathrm{~mm}$ ) was created by also taking into account the Meteo Office data on precipitation at station posts.

\section{Impact of seismicity on the development of landslide processes}

The carpathian region features with a considerable seismic activity. Annually, more than 10 earthquakes with the magnitude from 0.6 to 2 and greater is recorded there. On average, the earthquakes with magnitude 2.5-3 occur, accompanied with macroseismic effects (intensity is 5-6 points) occur every 5-10 years. Every 60-100, years one or two major earthquakes occur (with the magnitude up to 4-4.7) either locally, or with epicenters on the adjacent territory of Slovakia, Romania or Hungary, which have the intensity impact of up to 7 points within the area.

The study on the impact of this factor on the hazard phenomena activation was performed on the basis of an analysis of historic data (1797-2003) and instrumentation records (1961-2003). Nine earthquakes with the magnitude from 2.9 to 4.7 were recorded for the period 1797-2003. According to integral macroseismic data, the Mukachevo region is subject to EQ intensities of 3, 4 and 5-6 points, and Svalyava region is prone to EQ's with 3-7 points of intensity. The instrumentation observation period
1961-2003 recorded 54 earthquakes in the Carpathian region of Ukraine. Most earthquakes with small magnitudes tend to concentrate near the Svalyava region.

The integral analysis of the above-mentioned data showed that the subzones of increased seismicity correspond to predominantly subsiding areas of the Earth surface, or, at least, to the zones of contrast vertical movements. The most intense earthquakes are associated with Transcarpathian deep fault, featuring the most intense and differentiated subsidence, and horizontally extensional environment.

Such peculiarities of the areal geodynamics and seismicity may significantly impact triggering of hazard phenomena within the area: landslide intensification, distorted railway tracks, past accidents on pipelines etc. It was confirmed that each seismic shock displaces stabilized landslides in this area from 1 to $5 \mathrm{~mm}$.

\section{Regional modeling of landslide processes}

Landslide processes are the most relevant hazards for the region. Within the studied area, over 220 landslides were identified, 35 of which were active in the period from 1998 to 2001 due to massive inundations (Figure 2). Other landslides, formed during the last 30 years, are stabilized for the present moment. These landslides damaged and partially ruined the infrastructure facilities in the area, such as dwelling houses and buildings, roads, bridges and pipelines.

Our field investigations and analysis of landslide and erosion processes showed a complex interrelation of hydrometeorogeological and geological factors in the formation of such processes. Here, we briefly describe the main principles and approaches for their spatial modeling and prognosis. In order to determine the reference and prognostic features of the landslides and dominant factors of their formation, GIS technologies were used with database development for the conceptual model of the area with a number of layers and databases of attributive information.

The attributive table of landslides was filled with the morphometric data of landslide bodies including their form, dimensions, debris volume, distribution area, characteristics of the landslideprone hills and times of occurrence etc. The landslides were classified according to the following parameters: time of formation (separately considered stabilized historical and active landslides). 
A complex analysis of the landslide formation factors was performed on the basis of the cartographic studies. Each factor was ranked according to its impact on the landslide formation processes for the selected objects in accordance with the developed terrain assessment concept. Each object (landslide site) was assessed for correspondence to the said conditions. This resulted in a multidimensional model with object properties placed in different GIS layers.

In order to assess the impact of each factor on the landslide formation process, we calculated the eigen weight factors (information coefficients). Only the contributions from the most relevant agents are reported here, without subordinate agents. From the raw data table, pairwise correlation coefficients were calculated for the parameters, relevant for landslide formation. Using this information as input for the proximity matrix, the information coefficients were obtained. Figure 6 presents the impact of each of the considered factors on the landslide risk in the form of calculated information coefficients. These factors were combined to create an integrated prognosis map with assessment of the integrated hazard susceptibility for each location.
The objects of each layer were classified creating a unified scale for all classes (ranking from 1 to 4 ) to assess their impact on the landslide hazard. It should be mentioned that assigning weight coefficients to factors had to be performed in a self-consistent manner with adjustments made in the course of the model development. This procedure followed the algorithm of step-by-step factor grouping with use of expert analysis results taking into account analytical and onsite data.

The integrated map (Figure 7) was created by mathematical overlaying and enables to simultaneously take into account the agents under considerations, assessing sites and deriving a complex hazard model for the region. These results refer to the general impact of geological, geomorphological, and climatic factors on the formation of landslide processes. Genetic analysis and dynamics of landslides can be further studied only after detailed onsite investigations revealing the priority of different factors and their impact on the landslide formation. The values of dynamic factors can essentially affect their grouping and weight assignment for the landslide hazard assessment.

\section{factor weights}

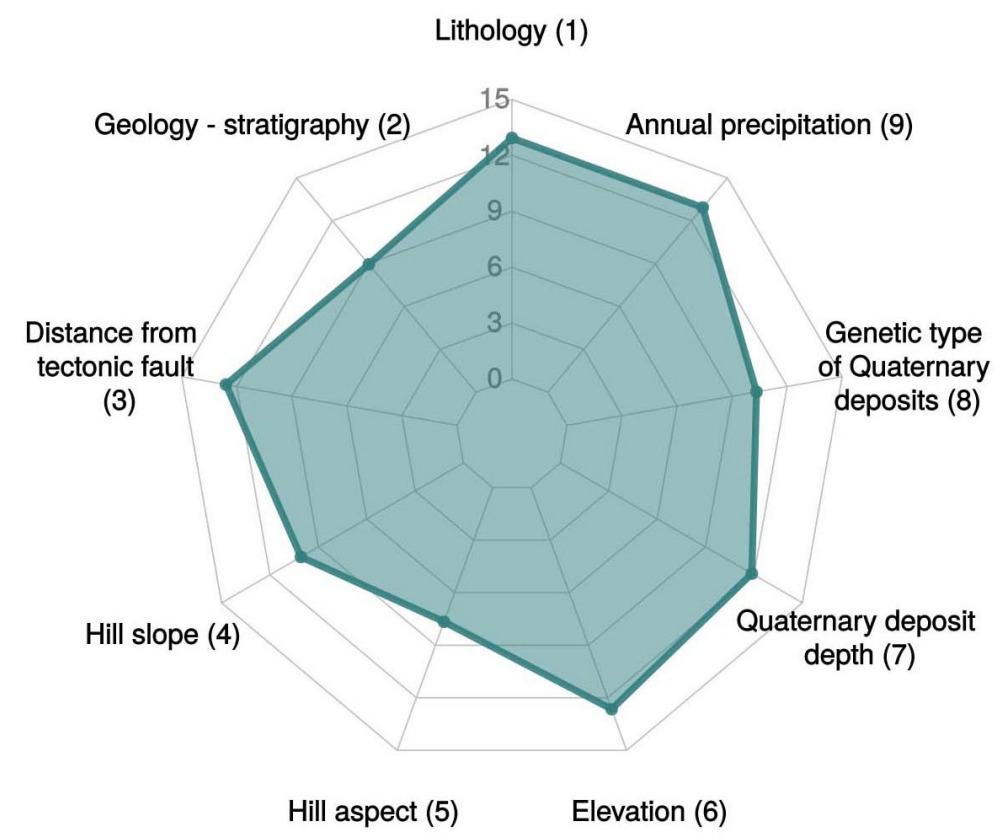

Figure 6. Factor weights (information coefficients) of relevant geological parameters for landslide hazard prognosis 


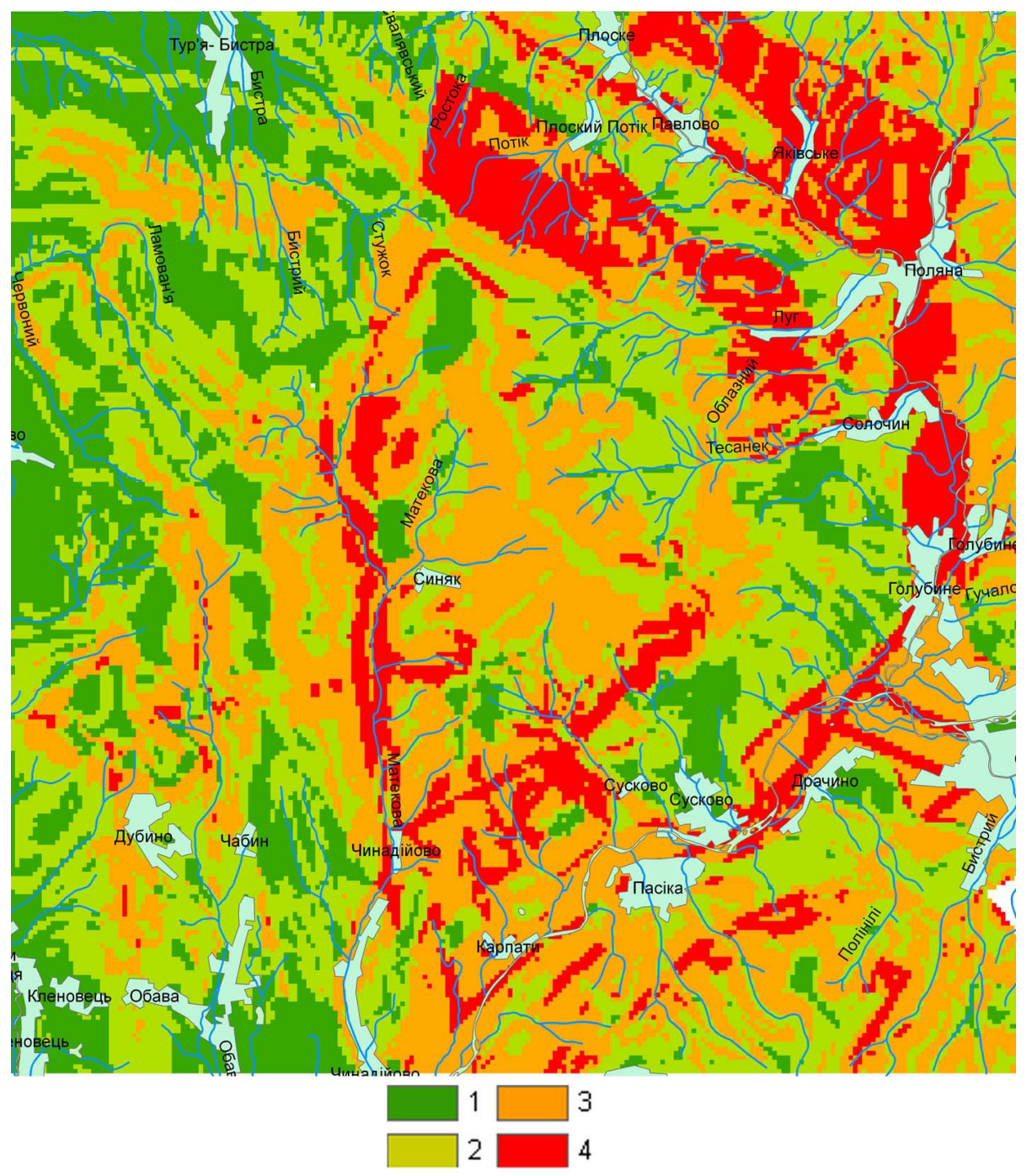

Figure 7. Integral landslide susceptibility model within the studied area of Ukrainian Carpathians

1 - areas with a low probability of landslides formation; 2 - area with the minimum number of landslides; 3 -areas with medium potential of landslides; 4 - areas of high risk of landslides.

\section{CONCLUSIONS}

The study on natural hazards in the Ukrainian Carpathians has revealed their close relation with the geological and geomorphological structures. Two main approaches were used for the natural hazards assessment. The first approach was based on statistical and GIS analyses of geo-environmental factors related to the occurrence of hazardous geological processes. The landslide susceptibility maps were created. The second approach assumes the local forecasting. It is based on field work and monitoring of landslides and erosion processes. We investigated the impact of lithology-stratigraphic, geomorphologic, structural, hydrogeologic, neotectonic and seismic factors on the emergence and development of gravitational landslide and erosional phenomena.
The zones of these processes are associated with definite formation complexes, characterizing by complicated spatial structure and history in accordance with physical characteristics of the corresponding rocks. Such distinct formations cause different impact on the natural hazards processes. The studies determined the composition and structure of the most dangerous landslides. In the Carpathian region there are predominantly structural landslides, landslides formed in inhomogeneous, anisotropic environment. Most landslides formed in the Oligocene flysch deposits affected by weak zones with varying orientation relating to slopes. The studies confirmed the special role of weak zones characterized by intense fracturing, brecciation and bedding of flysch deposits. Such zones are characterized by contrast permeability, strength properties of rocks decrease drastically 
within such zones, and large-scale landslide and erosion processes occur, especially in the case of subparallel location of such zones, relative to river valleys and slopes (Ivanik, 2015). The presence of weak zones affects the primary importance of tectonic factor at assessment of possible scale and intensity of landslides and debris flows. Certain combinations of geological and tectonic conditions can result in a complex interplay of river valleys and tectonic zones, which essentially affects the dynamics and morphology of landslide bodies.

The investigated region with complicated and heterogeneous geological background is a representative site for the development and refining of analytical techniques for the analysis of hazardous geological processes and can be recommended as a region for permanent monitoring. The processing of the cartography and on-site data showed that the most hazardous geological processes are characteristic for zones with combination of several hazard factors. The results of this research can be used for infrastructure planning and risk assessments in the Ukrainian Carpathians.

\section{REFERENCES}

1. Foster, C., Pennington, C.V.L., Culshaw, M.G., \& Lawrie, K. 2012. The national landslide database of Great Britain: development, evolu- tion and applications. Environmental Earth Sciences, 66(3), 941-953. https://doi.org/10.1007/ s12665-011-1304-5

2. Garcia-Rodriguez, M.J., Malpica, J.A., Benito, B., \& Diaz, M. 2008. Susceptibility assessment of earthquake-triggered landslides in El Salvador using logistic regression. Geomorphology, 95(3), 172-191. https://doi.org/10.1016/j.geomorph.2007.06.001

3. Ivanik, O.M. 2015. Classification of the Structural Landslides for the Natural Hazard Assessment. Paper presented at 77th EAGE Conference and Exhibition, Madrid, Spain. https://doi.org/10.3997/2 214-4609.201413442

4. Jaboyedoff, M., Oppikofer, T., Abellan, A., Derron, M.-H., Loye, M., Metzger, R., \& Pedrazzini, A. 2012. Use of LIDAR in landslide investigations: a review. Natural Hazards, 61(1), 5-28. https://doi. org/10.1007/s11069-010-9634-2

5. Pelletier, J.D. 2008. Quantitative modeling of Earth surface processes, Cambridge: University Press.

6. Varnes, D.J. 1978. Slope movement types and processes. Special Report 176: Landslids: Analysis and Control. Washington, DC: Transportation and Road Research Board, National Academy of Sciences, 11-33.

7. Varnes, D.J., Savage, W.Z. 1996. The Slumgullion earth flow: a large-scale natural laboratory. U.S. Geological Survey Bulletin 2130, pp. 95.

8. Wu, W. (Ed.). 2015. Recent Advances in Modelling Landslides and Debris Flows. Springer Intern. Publ. 323 p. doi: 10.1007/978-3-319-11053-0. 